\title{
Hepatic effect of the sub-chronic exposure to mosquito coil smoke in albino mice
}

\author{
Mshelia P. Paul, ${ }^{1}$ Rabiu M. Magaji \\ ${ }^{1}$ Department of Human Physiology, College of Medical Sciences, Abubakar Tafawa Balewa University, \\ Bauchi, Bauchi state; ${ }^{2}$ Department of Human Physiology, College of Health Sciences, Ahmadu Bello \\ University, Zaria, Kaduna state, Nigeria
}

\begin{abstract}
The hepatic effect of chronic inhalation of mosquito coil smoke in mice was investigated. Mosquito coil smoke is mosquito repellent incense made from dried pyrethrum powder. It is widely used in Africa, Asia and South America. Exposure to mosquito coil smoke may lead to coughing, sneezing, and inflammation of trachea, renal damage, weight loss, headache, itching and skin reaction. It decreases the protein biosynthetic activity of the liver. This could affect capacity of serum protein-mediated transport of various substances. Goldeer mosquito coil containing $0.03 \%$ Transfluthrin, manufactured in Kano, Nigeria and purchased in Zaria was used for this experiment. Twenty-four (24) male mice (20-40 g), were divided into four groups of six mice each and exposed for six weeks to mosquito coil smoke for 1, 2 and 3 hours in an inhalation chamber. The animals were humanely sacrificed and the their blood samples collected and analysed for the enzymes, Aspartate amino transferase (AST), Alanine aminotransferase (ALT) and Alkaline Phosphatase (ALP) as markers of Hepatic function. Also, their brain tissues were collected, homogenized and centrifuged and the supernatants assayed for oxidative stress biomarker, malondialdehyde (MDA) and antioxidant enzymes, superoxide dismutase (SOD) and Catalase (CAT). Data
\end{abstract}

Correspondence: Mshelia Philemon Paul, Department of Human Physiology, College of Medical Sciences, Abubakar Tafawa Balewa University, Bauchi, Nigeria.

Tel: +234.08063306768

E-mail: philmshel1@gmail.com

Key words: Mosquito coil, Mice, Liver enzymes, oxidative stress.

Contributions: MPP was involved in the conception and design, drafting of the article and final approval of the version to be published. RMM was involved in critically revising the article for important intellectual content.

Conflict of interest: The authors declare no potential conflict of interest.

Funding: none

Received for publication: 24 May 2018.

Revision received: 8 June 2018.

Accepted for publication: 17 June 2018.

This work is licensed under a Creative Commons Attribution NonCommercial 4.0 License (CC BY-NC 4.0).

CCopyright M.P. Paul et al., 2018

Licensee PAGEPress, Italy

Annals of African Medical Research 2018; 1:23

doi:10.4081/aamr.2018.23 were analysed using one way ANOVA and expressed as Mean \pm SEM with value of $\mathrm{P}<0.05$ considered statistically significant. The result showed that the mosquito coil smoke exposure in mice does not cause any significant change in liver enzymes, MDA and SOD. However, there were significant increases in CAT activity $(43.83 \pm 1.85)$ and $(41.67 \pm 1.36)$ as compared to control $(38.50 \pm 1.00)$

\section{Introduction}

Mosquito coil smoke is a mosquito repellent incense made from dried pyrethrum powder. It is widely used in Asia, Africa and South America. ${ }^{1}$ Each coil burns for several hours and are used in close proximity to persons requiring protection against mosquitoes bites. $^{2}$ It poses a serious public health hazards and ecological challenges because of the effects associated with their use, especially innocuous and chronic inhalation of the fumes. ${ }^{3}$ It has also been reported that burning one mosquito coil would release the same amount of particulate matters as burning 75-137 cigarettes and emission of formaldehyde as high as that released from burning 51 cigarettes. ${ }^{4}$ It could also lead to coughing, sneezing, inflammation of trachea, renal damage, body weight reduction, headache, itching and skin reaction. ${ }^{1}$ With malaria and other mosquito-borne diseases a health challenge in tropical areas, mosquito coil usage has increased in recent decades and the annual world consumption was estimated at 32 billion coils as at the year 2000.5 The endemic nature of malaria infestation in Nigeria and the economic implication of being infected have left many families with no choice other than to look for any way possible to avoid it. The mosquito coil is the commonest and cheapest methods used by many families to drive away mosquitoes from sleeping rooms.

Enzymes catalyse specific biochemical reactions. ${ }^{6}$ And they always function intracellularly and have no physiologic use in the plasma. In healthy individuals, the levels of these enzymes are fairly constant, and represent a steady state in which the rate of release from damaged cells into the plasma is balanced by an equal rate of its removal from the plasma. The presence of elevated activity in plasma indicates tissue damage that is accompanied by increased release of intracellular enzymes. ${ }^{7-8}$ Elevated hepatic enzymes and markers of oxidative stress are important biochemical markers of liver damage and disease state. This study is therefore aimed at investigating the effect of mosquito coil smoke on Hepatic enzymes and oxidative stress.

\section{Materials and Methods}

Twenty-four adult mice weighing 20-40 g were obtained from the National Institute of Trypanosomiasis and Oncocerciasis Research (NITOR), Kaduna, Nigeria and transported to Zaria, Nigeria where they were allowed to get accustomed to the environ- 
ment for two weeks at the Department of Human Physiology, Ahmadu Bello University, Zaria, Kaduna State, Nigeria. They were fed mainly with grower mash and water ad Libitum. Goldeer ${ }^{\circledR}$ mosquito coil containing 0.03 transfluthrin and manufactured in Kano, Nigeria was obtained from a retail shop in Zaria, Nigeria. The experimental animals were divided into four groups of six mice each. Group 1 was exposed to environmental air only while mice in groups 2, 3 and 4 were exposed to mosquito coil smoke for 1, 2 and 3 hours daily for 6 weeks respectively, in a partially ventilated inhalation chamber $(2.00 \times 0.98 \times 1.55 \mathrm{~m})$. After which the animals were humanely sacrificed and the blood samples collected were assayed for liver enzymes, aspartate transaminase (AST), alkaline phosphotase (ALP) and alanine transaminase (ALT). Whole brain tissues collected were homogenized and centrifuged and the supernatants assayed for oxidative stress biomarker, malondialdehyde (MDA) and antioxidant enzymes, superoxide dismutase (SOD) and catalase (CAT). Data were analyzed using one-way ANOVA and expressed as Mean \pm SEM with value of $\mathrm{P}<0.05$ considered statistically significant.

\section{Results}

All experimental protocols were conducted in accordance with the Ahmadu Bello University research policy, ethics and regulations governing the care and use of experimental animals. The summary results are presented in Tables 1 and 2 .

\section{Discussion and Conclusion}

The result as presented in Table 1 showed no significant increase in the liver enzymes, indicating no liver damage as a result of mosquito coil smoke exposure in this experiment. This is not in agreement with several studies, ${ }^{9,10}$ that have shown the

Table 1. Table showing the effect of mosquito coil smoke on liver enzymes.

\begin{tabular}{lcccc} 
Groups & N. & AST (IU/L) & ALT (IU/L) & ALP (IU/L) \\
Group 1* & 6 & $11.50 \pm 0.43$ & $51.83 \pm 1.96$ & $116.17 \pm 15.85$ \\
Group 2** & 6 & $10.67 \pm 0.42$ & $55.00 \pm 1.06$ & $103.17 \pm 2.58$ \\
\hline Group 3*** & 6 & $11.00 \pm 0.26$ & $52.17 \pm 1.38$ & $128.83 \pm 15.51$ \\
Group 4**** & 6 & $10.17 \pm 0.20$ & $53.50 \pm 0.78$ & $112.79 \pm 5.76$ \\
\hline
\end{tabular}

$\mathrm{ALT}=$ Alanine amino transferase, $\mathrm{AST}=$ Aspartate amino transferase, $\mathrm{ALP}=$ Alkaline phosphatise . *Exposed to environmental air; **Exposed to mosquito coil smoke, 1 hour daily for 6 weeks; ***Exposed to mosquito coil smoke, 2 hours daily for 6 weeks; ${ }^{* * * *}$ Exposed to mosquito coil smoke, 3 hours daily for 6 weeks.

Table 2. Table showing mosquito coil smoke effect on oxidative stress biomarker.

\begin{tabular}{lcccc} 
Groups & N. & MIDA $(\mu m o / / L)$ & SOD (IU/L) & CAT (IU/L) \\
Group 1* & 6 & $1.50 \pm 0.13$ & $1.82 \pm 0.06$ & $38.50 \pm 0.92$ \\
Group 2** & 6 & $1.72 \pm 0.15$ & $2.10 \pm 0.17$ & $43.83 \pm 1.85^{\mathrm{a}}$ \\
\hline Group 3*** & 6 & $1.57 \pm 0.16$ & $2.00 \pm 0.12$ & $34.00 \pm 2.31^{\mathrm{a}}$ \\
Group 4**** & 6 & $1.57 \pm 0.09$ & $2.15 \pm 0.13$ & $41.67 \pm 1.36^{\mathrm{a}}$ \\
\hline
\end{tabular}

Values with ${ }^{\mathrm{a}}$ superscripts are statistically significant $(\mathrm{P}<0.05)$ as compared to control; $\mathrm{MDA}=$ malondialdehyde, $\mathrm{SOD}=$ superoxide dismutase, $\mathrm{CAT}=$ Catalase. ${ }^{*}$ Exposed to environmental air; ${ }^{* *}$ Exposed to mosquito coil smoke, 1 hour daily for 6 weeks; ***Exposed to mosquito coil smoke, 2 hours daily for 6 weeks; ****Exposed to mosquito coil smoke, 3 hours daily for 6 weeks. activity of all liver enzymes increased. They investigated the toxicological effects of smoke from locally manufactured mosquito coil insecticides of different brands on male albino rats. The animals were exposed to the smoke for different duration of exposure ranging from 2 to 16 weeks for up to 8 hours daily. Mosquito coil smoke produced significant increase $(\mathrm{P}<0.05)$ in the level of AST, ALP and ALT in all the exposed groups. And the investigation of Al-Mamun et al. ${ }^{11}$ who studied the biochemical and histological alterations induced by the smoke of mosquito coil on mice model, in which a total of twenty four Swiss albino mice were allowed to inhale the smoke of mosquito coil at different duration per day for 120 days. By the end of treatment period, blood sample was drawn from each mouse and blood biochemical parameters including alanine transaminase (ALT), aspartate transaminase (AST) were analysed. Their result indicates that the activity of two key hepatic enzymes, ALT and AST were increased significantly $(\mathrm{P}<0.05)$ by $89 \%$ and $85 \%$, respectively in mice exposed to the smoke for 3 hour/day.

The significant increase in CAT in groups 2, 3 and 4 of this study, which were exposed to mosquito coil smoke daily for 1,2 and 3 hours respectively over a duration of 6 weeks (Table 2) could be due to slight antioxidant activity which might have taken place to bring about balance. This didn't agree with our previous study, ${ }^{12}$ in which after investigating the effect of sub-chronic exposure to mosquito coil smoke on motor coordination in mice, using twentyeight adult mice and grouped into four with seven mice each and were exposed for 1, 2 and 3 hours daily for 6 weeks, show no significant increase in CAT activity.

And this was also collaborated by Scalios, ${ }^{13}$ who showed that mosquito repellent exposure could lead to decrease in CAT which exhibits a higher affinity for $\mathrm{H}_{2} \mathrm{O}_{2}$ by degrading it to $\mathrm{H}_{2} \mathrm{O}$ and $\mathrm{O}_{2}$, limiting the damage of $\mathrm{H}_{2} \mathrm{O}_{2}$ before it could diffuse to other parts of the cell. However, this study agrees with Chizefin et al. ${ }^{14}$ who reported no significant increase in ALT in insecticidal workers exposed to pyrethroids.

The lack of significant increase in the liver enzymes to the mosquito coil smoke exposure in this study could be as a result of the duration and time of exposure to the mosquito coil smoke. Significant result might be recorded with longer duration and time of exposure.

In conclusion, short duration of exposure to mosquito coil smoke may not affect liver function.

\section{References}

1. Liu W, Zhang J, Hashim JH, et al. Mosquito coil emissions and health implications. Environ Health Perspect 2003;111:1454.

2. Garba SH, Shehu MM, Adelaiye AB. Toxicological effects of inhaled mosquito coil smoke on the rat spleen: A haematological and histological study. J Med Sci 2007;7:94-9.

3. Taiwo VO, Nwagbara ND, Suleiman R, et al. Clinical signs and organ pathology in rats exposed to graded doses of pyrethroids-containing mosquito coil smoke and aerosolized insecticidal sprays. Afr J Biomed Res 2008;11.

4. Shu-Chen C, Ruey-Hong W, Li-Jie S, et al. Exposure to mosquito coil smoke may be a risk factor for lung cancer in Taiwan. J Epidemiol 2008;18:19-25.

5. Mshelia PP, Magaji RA, Dikko AU. Cognitive effect of the sub-chronic exposure to mosquito coil smoke in mice. IOSR J Pharm Biol Sci 2013;8:26-30.

6. Crook MA. Clinical chemistry and metabolic medicine. 7th ed. UK; Williams and Wilkins Publishers; 2006. pp. 199-213. 
7. Pamela CC, Harvey RA, William L. Lippincott biochemistry, 3rd ed. New York: Wilkins Company; 2005.

8. Offor CE. Effect of smoke from mosquito coil on serum aspartate transaminase, alanine transaminase and alkaline phosphatase activities in male albino rats. Int J Curr Res Acad Rev 2014;2:97-100.

9. Taiwo Idowu E, Aimufua OJ, Yomi-Onilude E, et al. Toxicological effects of prolonged and intense use of mosquito coil emission in rats and its implications on malaria control. Revista de Biologia Tropical 2013;61:1463-73.

10. Abubakar MG, Hassan IG. Toxicological effects of some mosquito coil brands in experimental rats. J Toxicol
2007;14:55-60.

11. Al-Mamun MA, Rahman MA, Rahman $\mathrm{MH}$, et al. Biochemical and histological alterations induced by the smoke of allethrin based mosquito coil on mice model. BMC Clinical Pathol 2017;17:19.

12. Mshelia PP, Magaji RA, Dikko AU. Sub-chronic Exposure to Mosquito coil Smoke in Mice: Effect on Motor Coordination. J Biol Med 2017;11;2.

13. Scalios JG. The rise of ROS. Trends Biochem Sci 2002;22:483-6.

14. Chizefin KN, Plant JC, Singh T. Pesticide in biochemistry and physiology 1992.20:294. 